\title{
Muckle-Wells Syndrome
}

National Cancer Institute

\section{Source}

National Cancer Institute. Muckle-Wells Syndrome. NCI Thesaurus. Code C119054.

An autoinflammatory disease caused by mutations in the NLRP3 gene which encodes

cryopyrin. It is characterized by recurrent episodes of urticaria and fever which develop in infancy. It may lead to sensorineural hearing loss and/or amyloidosis. 